\title{
Relative Blood Volume Monitoring during Renal Replacement Therapy in Critically III Patients with Septic Shock: A Preliminary Report
}

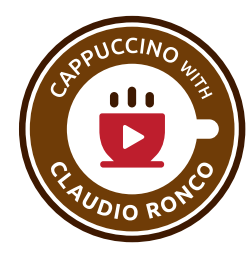

\author{
Susanne Kron ${ }^{a}$ Til Leimbach $^{b}$ Reinhard Wenkel ${ }^{b} \quad$ Ulrike Thieme $^{b}$ \\ Hartmut Kern ${ }^{c}$ Joachim Kron ${ }^{b}$ \\ ${ }^{a}$ Department of Nephrology, Charite Campus Mitte, Universitätsmedizin Berlin, ${ }^{\mathrm{b}} \mathrm{KfH}$ Kidney Center Berlin-Köpenick, \\ and ${ }^{\mathrm{C}}$ Department of Anesthesiology and Intensive Care, DRK Kliniken Berlin-Köpenick, Berlin, Germany
}

\section{Key Words}

Relative blood volume monitoring $\cdot$ Septic shock $\cdot$ Renal replacement therapy · Acute kidney injury · Outcome

\begin{abstract}
Background: Volume management during renal replacement therapy (RRT) in septic shock is always in the conflict between aggravating hypovolemia by undue ultrafiltration (UF) and insufficient reduction of fluid overload which is associated with adverse outcome. Relative blood volume (RBV) monitoring could be helpful for timely transition from fluid resuscitation to fluid removal. Methods: Data of RBV were continuously monitored and used for guidance of UF and fluid resuscitation in 21 consecutive patients with severe septic multiple organ failure. RRT was applied with extended daily hemodiafiltration for median $11 \mathrm{~h}$ (range 6-23). Changes in RBV were analyzed during the first 4 treatment sessions. Results: During 26 treatments, RBV monitoring revealed an internal volume loss substituted by a median infusion volume of $2.38 \mathrm{I}$ (maximum $8.07 \mathrm{I}$ ) per treatment to keep the RBV constant. In the remaining 40 sessions, a median net-UF of $1.00 \mathrm{I}$ (range 0.40-4.40) was achieved. In the first 2 days predominantly substitution was necessary whereas from the third day UF became increasingly possible. The 28-day survival rate was $81 \%$. Conclusion: Blood volume monitoring
\end{abstract}

proved to be an easy and feasible tool for safe guidance of fluid management maintaining the balance between UF and vascular refilling.

Video Journal Club 'Cappuccino with Claudio Ronco' at http://www.karger.com/?doi=433415. @ 2015 S. Karger AG, Basel

\section{Introduction}

The treatment of patients with septic multiple organ failure poses a challenge for all the clinicians involved. Septic acute kidney injury (AKI) remains a diagnosis with the poorest prognosis as $>70 \%$ of patients die [1]. In a prospective pilot study of our working group published in 2012 [2], application of online high-volume hemodiafiltration (HDF) in patients with septic multiple organ failure seemed to account for a favorable outcome; the 28 -day survival rate was $81 \%$. At that time, the survival benefit in the early phase of septic shock was attributed to the high convective dose of RRT $(208 \mathrm{ml} / \mathrm{kg} / \mathrm{h})$. But the assumption of 'more being better' in this setting is rather not supported by recent data [3]. In a randomized study enrolling 280 patients with sepsis and AKI, Zhang et al. [4] found no differences in survival at 28,60 and 90 days with treatment doses of 50 and $85 \mathrm{ml} / \mathrm{kg} / \mathrm{h}$. A subgroup

\section{KARGER 125\%}

(c) 2015 S. Karger AG, Basel

0253-5068/15/0402-0133\$39.50/0 
analysis of septic shock patients treated with the higher dose did not indicate any survival benefit either. The controlled randomized IVOIRE study comparing treatment doses of 35 and $70 \mathrm{ml} / \mathrm{kg} / \mathrm{h}$ in 140 patients with septic shock with respect to the 28-day survival also failed to prove a survival benefit in the high volume group [5]. Given the results of these 2 large controlled randomized studies, it seems questionable to attach the main importance concerning the survival benefit in our study to the high treatment dose. Therefore, we reviewed our data critically with respect to further potential differences and biases.

It is of note, indeed, that our trial was conducted using dialysis devices featuring a monitor for the continuous measurement of relative changes in blood volume. Consequently, this variable was recorded in all the treatment sessions. The information of relative blood volume (RBV) was additionally used for managing fluid balance and for adjusting ultrafiltration (UF) rate. A post hoc analysis of our data was performed to evaluate an influence of blood volume monitoring on outcome and prognosis of septic shock.

\section{Materials and Methods}

\section{Patients}

Twenty-one consecutive patients with septic multiple organ failure were enrolled in a prospective observational study. Detailed information is published elsewhere [2]. Criteria for inclusion were results of the Acute Physiology and Chronic Health Evaluation II (APACHE II) score and of the Simplified Acute Physiology Score II (SAPS II) being $>25$ and $>50$, respectively. All patients required mechanical ventilation, vasopressor support, and suffered from anuric or oliguric AKI. Baseline characteristics are presented in table 1 .

\section{Renal Replacement Therapy}

Renal replacement therapy (RRT) was applied with extended daily online HDF for 6-23 h (median 11) using the AK 200 Ultra $S$ dialysis machine (Gambro, Lund, Sweden) in the Ultracontrol pre-dilution mode [2]. Vascular access was obtained with an 11-F dual-lumen catheter inserted in the internal jugular or femoral vein. Blood flow rate was kept at $200 \mathrm{ml} / \mathrm{min}$. The median convective volume was $173 \mathrm{l} /$ day with a mean exchange rate of $17.8 \pm 3.7$ $\mathrm{l} / \mathrm{h}$ and $208 \pm 66 \mathrm{ml} / \mathrm{kg} / \mathrm{h}$, respectively. Blood flow rate was kept at $200 \mathrm{ml} / \mathrm{min}$.

The dialysate sodium concentration was $140 \mathrm{mmol} / \mathrm{l}$, potassium, calcium and bicarbonate individually adjusted according to serum levels of the patients.

\section{RBV Monitoring}

A blood volume monitor is a standard feature of the dialysis device AK 200 Ultra S, enabling continuous recording of changes in the RBV. Technically, the system is based on an optical indirect
Table 1. Patient characteristics at baseline

Characteristics $(\mathrm{n}=21)$
Age, years

Gender (female), n (\%)

Weight, $\mathrm{kg}$

APACHE II

SAPS II

Sequential organ failure assessment

Urine output 24-h pre first $\mathrm{HDF}, \mathrm{ml} / \mathrm{h}$

Creatinine, $\mu \mathrm{mol} / \mathrm{l}$

Urea, $\mathrm{mmol} / \mathrm{l}$

C-reactive protein, $\mathrm{mg} / \mathrm{dl}$

Leucocyte, Gpt/l

\author{
$70(46-87)$ \\ $7(33 \%)$ \\ $89.0 \pm 15.4$ \\ $33.6 \pm 5.8$ \\ $68.4 \pm 9.3$ \\ $15.1 \pm 2.7$ \\ $5(0-21.5)$ \\ $349 \pm 101.0$ \\ $20.0 \pm 8.1$ \\ $34.2 \pm 10.0$ \\ $24.2 \pm 12.1$
}

Data are represented as median (range) for age and urine output and as mean \pm SD for other continuous data unless otherwise mentioned.

hemoglobin measurement [6]. An optoelectronic instrument measures the absorption of near-infrared monochromatic light (wavelength $810 \mathrm{~nm}$ ) transmitted through blood. A measuring tube is incorporated into the arterial blood line (located before the predilution substitution is administered). The absorption is directly related to the hemoglobin concentration. Removal of plasma volume leads to an increase in the relative hemoglobin concentration, thus causing an increased absorption of light. This increase in absorption is translated into a relative reduction in blood volume and continuously displayed on the monitor. Changes in RBV were analyzed during the first 4 treatment sessions.

\section{Volume Management}

Nephrologists and intensivists agreed on volume resuscitation and UF at the beginning of treatments, as well as on changes during their courses. Information of RBV changes during the treatment session was used in addition to clinical and other monitoring data to manage the fluid balance and to adjust the UF rate. There was no pre-specified protocol for volume management according to the blood volume data.

\section{Statistics}

All statistical analyses were performed with SPSS statistics 20 (SPSS Inc., Chicago, Ill., USA). Data are presented as appropriate. Normally distributed data are provided as means \pm SDs and all other data as medians and ranges.

\section{Results}

During the first week of treatment 3 out of 21 patients died. In one of these 3 patients, blood volume monitoring could not be performed. Seventeen out of 21 patients survived for 28 days ( $81 \%)$. The 90 -day survival rate was $52 \%$ (11 of 21 ) compared to a survival rate of $19 \%$ predicted by 
Fig. 1. RBV changes during 66 treatment

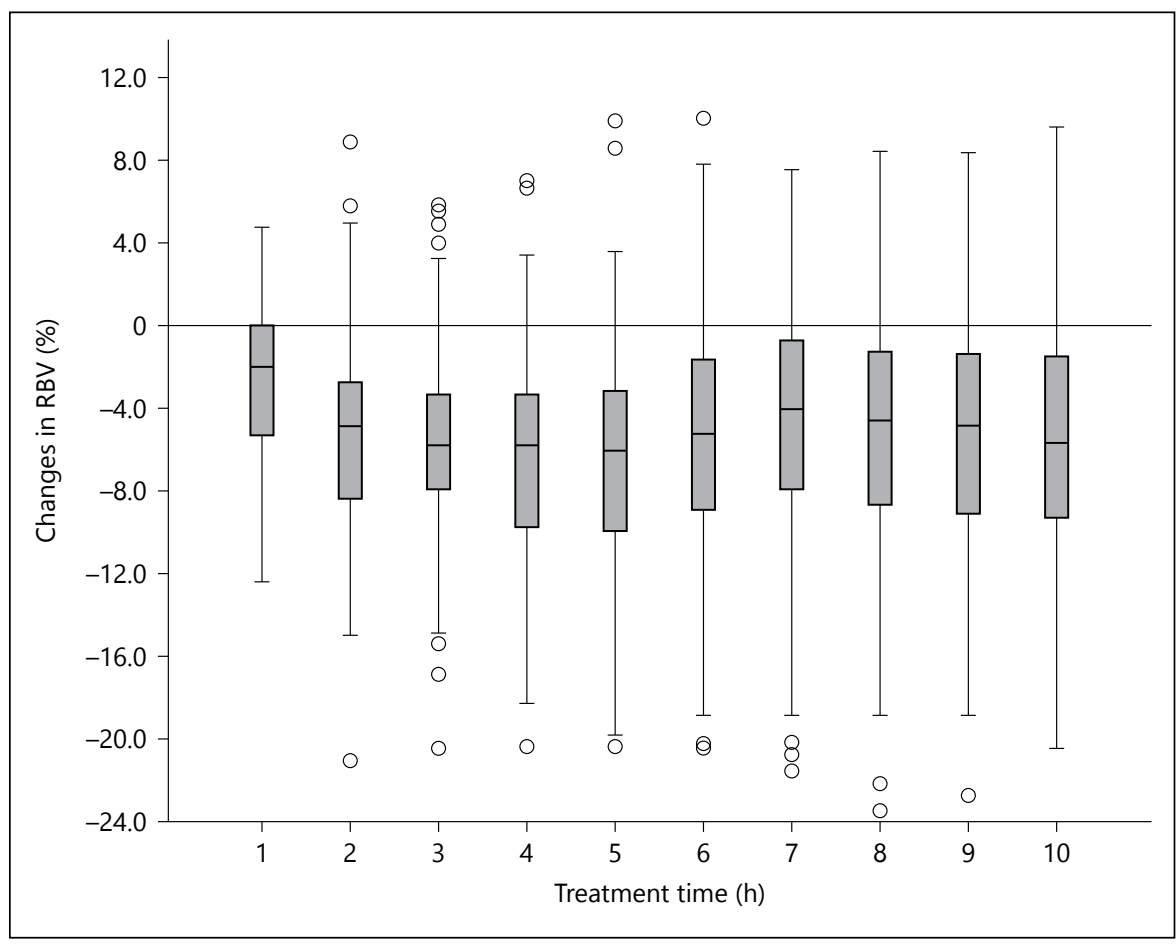
sessions.

APACHE II and SAPS II scores. All survivors recovered renal function. Three patients died after recovering their renal function.

Vasopressor need decreased and hemodynamics improved significantly during the treatment sessions [2].

In 21 patients, 80 treatments were performed during the first 4 days. One patient died after 2 days, another after 3 days, 1 patient recovered renal function after 3 days. Blood products interfering with the evaluation of RBV changes were transfused in 14 treatment sessions. Consequently, RBV data could only be analyzed in 66 treatments.

Twenty-six treatment sessions were performed without UF for reasons of apparent fluid requirement in the early phase of sepsis. During these treatments, RBV monitoring revealed an internal volume loss substituted by a median infusion volume of 2.381 (maximum 8.07) per treatment to keep the RBV constant. In the remaining 40 sessions, a median net-UF of 1.001 (range $0.40-4.40$ ) was achieved. During 10 sessions, UF was reduced, and in 7 sessions, UF was increased. Changes in RBV during all the 66 treatments are displayed in figure 1. After the third treatment hour, blood volume was maintained at a steady state indicating a balance between refilling and fluid removal. At the end of the treatment sessions, the mean change in RBV was 5.6\% ( \pm 7.3$)$. Different therapeutic targets for fluid balance contributed to the considerable vari- ation of this variable. In the first 2 days predominantly substitution was necessary whereas from the third day UF became increasingly possible (table 2 ; fig. $2 \mathrm{~d}$ ).

Figure 2 shows the changes in RBV, fluid balance, mean arterial pressure (MAP) and norepinephrine (NE) dose during the treatment sessions.

\section{Discussion}

The septic pathophysiology of capillary leak resulting in considerable volume loss into the interstitial space accounts for the patient's typical state of intravascular volume depletion and severe fluid overload. On one hand, volume resuscitation is essential for maintaining circulation and organ perfusion [7-10], whereas on the other hand, fluid accumulation is associated with an impaired outcome [8-14].

Volume management by RRT in septic shock is, therefore, always caught up in the conflict of aggravating hypovolemia by undue UF and insufficient reduction of fluid overload, thus contributing to a poorer prognosis [15]. The continuously available bedside information of RBV might aid clinicians in analytic rather than intuitive decision making concerning fluid management. Our data showed an internal volume loss of up to 81 during a ses- 


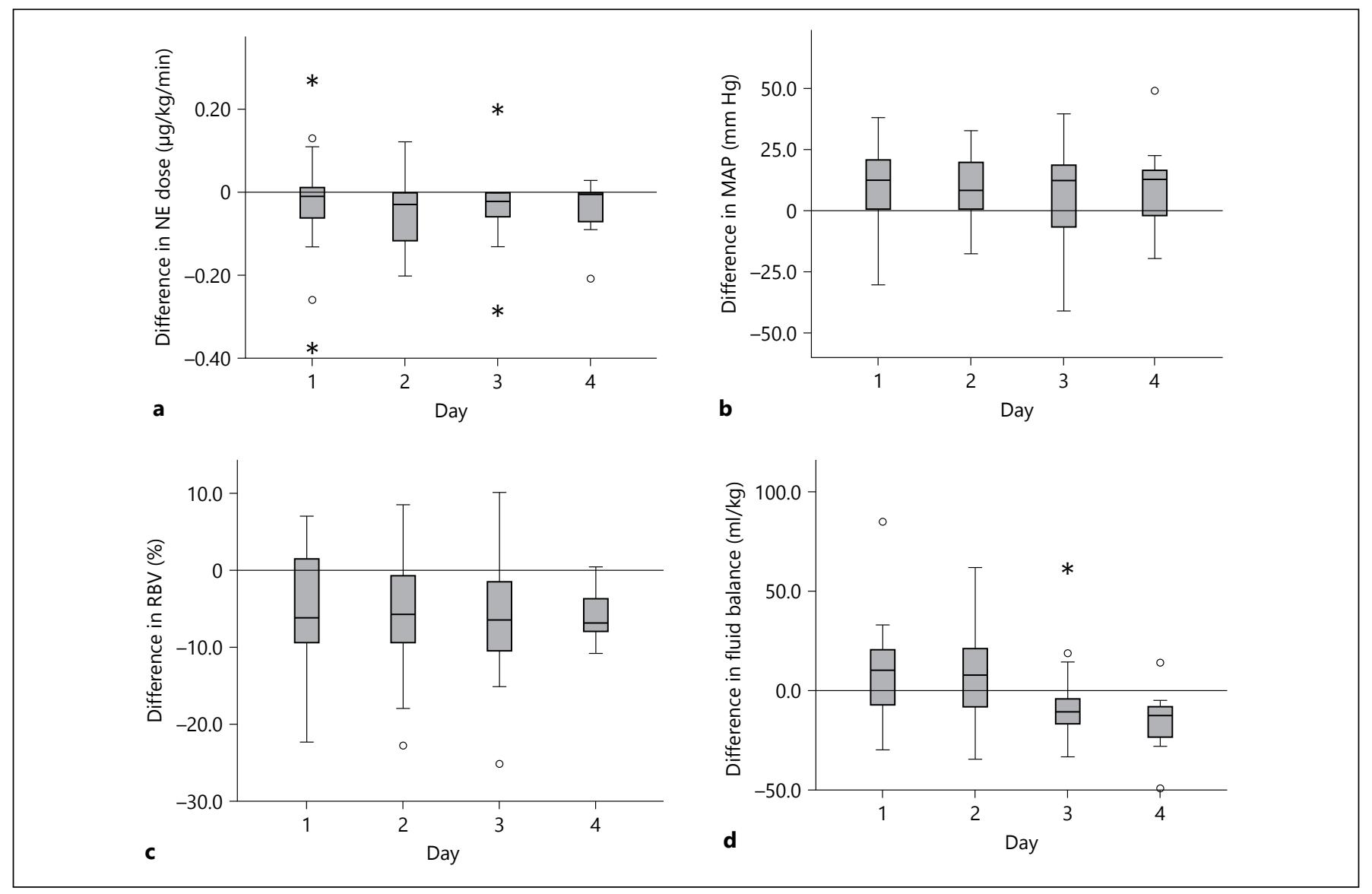

Fig. 2. Changes of NE dose (a), MAP (b), RBV (c) and fluid balance (d) during the treatment sessions. Whereas the NE dose remained almost unchanged, MAP increased during the treatments on all

Table 2. Fluid balance during the first 4 treatment sessions

\begin{tabular}{lllr}
\hline $\begin{array}{l}\text { Session } \\
\text { no. }\end{array}$ & $\begin{array}{l}\text { Treatments } \\
\text { with UF, \% }\end{array}$ & \multicolumn{1}{l}{ Fluid balance during the sessions } \\
\cline { 3 - 4 } & & 1 & $\mathrm{ml} / \mathrm{kg}$ body weight \\
\hline 1 & 20 & $+1.06(+8.07$ to -1.50$)$ & $+11.4(+84.9$ to -17.5$)$ \\
2 & 43 & $+0.59(+5.85$ to -2.60$)$ & $+8.0(+61.6$ to -34.7$)$ \\
3 & 80 & $-1.00(+5.50$ to -3.00$)$ & $-10.6(+61.1$ to -33.3$)$ \\
4 & 80 & $-1.36(+1.38$ to -4.40$)$ & $-10.8(+15.3$ to -48.9$)$ \\
\hline
\end{tabular}

+ denotes infusion and - denotes UF. Data are represented as median (range).

sion of RRT without UF. Encouraging such large volume substitution in patients already presenting with clinically severe fluid overload might not look sensible but in this study may have saved the patients' lives. In other treatments, RBV monitoring encouraged an increased UF vol-
4 days. The decrease in RBV during treatments was similar on all 4 days, but fluid balance was positive in the first 2 days, whereas from the third day fluid withdrawal became increasingly possible.

ume up to 2.41 . Overall, in this study, adjusting UF requirements and volume resuscitation according to RBV data resulted in a relatively steady state of RBV during RRT. This could have contributed to the beneficial survival in our study.

RBV monitoring is a standard feature of modern dialysis devices. But, there are only scarce data on RBV monitoring in AKI [16-20]. In some studies, measuring RBV in acute RRT seemed to allow higher UF rates [1720], but there was no evidence for favorable hemodynamic stability or reduction in episodes of intradialytic hypotension. In those critically ill patients, apparently other parameters were of more influence [20]. To date, there are no studies concerning RBV monitoring in critically ill patients aimed at patient's survival or especially focusing on patients with septic shock.

RBV monitoring is not restricted to dialysis machines with incorporated devices like AK 200 in our study. 
Stand-alone devices (Crit-Line, FMC, Kaysville, Utah, USA) are available and can be used in all RRT procedures (continuous or intermittent) with their different blood line systems [21]. The disposable Crit-Line blood chamber can be placed between the catheter and the arterial blood line (if pre-dilution HDF is used) or between the arterial blood line and the dialyzer. Possible dilution by infusions upstream of the chamber has to be avoided. The combination with venous oxygen saturation measurement is an additional advantage of this device [22].

This preliminary report certainly suffers several limitations. RBV data were not recorded for the original study [2]. They were collected as a post hoc analysis from patient's treatment documentation. There was no study protocol presetting the actual adjustment of UF according to the RBV data in particular. Besides including only a small number of patients, this survey did not have a control group. Performing RRT as high-volume HDF forms a relevant bias.

One important limitation of the method itself has to be taken into consideration especially when applied in intensive care - a constant hemoglobin level throughout the treatment session is an absolute requirement. In our study, $20 \%$ of treatments could not be analyzed for that reason. In cases of actual or impending bleeding events, the method may not be used for feedback control at all. Furthermore, greater osmotic changes [23], hemolysis $[21,24]$ and lipid emulsions [25] can influence the measurement. Optical measurement systems are especially affected by such artifacts. Therefore, the uncritical use of the displayed data bears relevant risks. The obtained data must always be interpreted in accordance with the patient's clinical state.

In conclusion, this is the first preliminary report concerning blood volume monitoring in RRT in patients with septic shock. RBV monitoring proved to be an easy and feasible tool for safe guidance of fluid management, thus maintaining the balance between UF and vascular refilling providing a possible addition to intensivists' inventory. Larger, prospective and preferably randomized studies are needed.

\section{Disclosure Statement}

The authors have no conflicts of interest to declare.

\section{References}

1 Bagshaw SM, Uchino S, Bellomo R, Morimatsu H, Morgera S, Schetz M, Tan I, Bouman C, Macedo E, Gibney N, Tolwani A, Oudemansvan Straaten HM, Ronco C, Kellum JA: Septic acute kidney injury in critically ill patients: clinical characteristics and outcomes. Clin J Am Soc Nephrol 2007;2:431-439.

2 Kron J, Kron S, Wenkel R, Schuhmacher HU, Thieme U, Leimbach T, Kern H, Neumayer $\mathrm{HH}$, Slowinski T: Extended daily on-line high-volume haemodiafiltration in septic multiple organ failure: a well-tolerated and feasible procedure. Nephrol Dial Transplant 2012;27:146-152.

3 Lins RL: RRT treatment for AKI: is more always better? Nephrol Dial Transplant 2012; 27:4252-4255.

4 Zhang P, Yang Y, Lv R, Zhang Y, Xie W, Chen $\mathrm{J}$ : Effect of the intensity of continuous renal replacement therapy in patients with sepsis and acute kidney injury: a single-center randomized clinical trial. Nephrol Dial Transplant 2012;27:967-973.

5 Joannes-Boyau O, Honoré PM, Perez P, Bagshaw SM, Grand H, Canivet JL, Dewitte A, Flamens C, Pujol W, Grandoulier AS, Fleureau C, Jacobs R, Broux C, Floch $\mathrm{H}$, Branchard O, Franck S, Rozé H, Collin V, Boer W, Calderon J, Gauche B, Spapen HD, Janvier G, Ouattara A: High-volume versus standard-volume haemofiltration for septic shock patients with acute kidney injury (IVOIRE study): a multicenter randomized controlled trial. Intensive Care Med 2013;39: 1535-1546.

6 Paolini F, Mancini E, Bosetto A, Santoro A: Hemoscan: a dialysis machine-integrated blood volume monitor. Int J Artif Organs 1995; 18:487-494.

7 Rivers E, Nguyen B, Havstad S, Ressler J, Muzzin A, Knoblich B, Peterson E, Tomlanovich M: Early goal-directed therapy in the treatment of severe sepsis and septic shock. N Engl J Med 2001;345:1368-1377.

8 Prowle JR, Echeverri JE, Ligabo EV, Ronco C, Bellomo R: Fluid balance and acute kidney injury. Nat Rev Nephrol 2010;6:107-115.

9 Prowle JR, Kirwan CJ, Bellomo R: Fluid management for the prevention and attenuation of acute kidney injury. Nat Rev Nephrol 2014; 10:37-47.

10 Kelm DJ, Perrin JT, Cartin-Ceba R, Gajic O, Schenck L, Kennedy CC: Fluid overload in patients with severe sepsis and septic shock treated with early goal-directed therapy is associated with increased acute need for fluidrelated medical interventions and hospital death. Shock 2015;43:68-73.

11 Payen D, de Pont AC, Sakr Y, Spies C, Reinhart $\mathrm{K}$, Vincent JL: A positive fluid balance is asso- ciated with a worse outcome in patients with acute renal failure. Crit Care 2008;12:R74.

12 Bouchard J, Soroko SB, Chertow GM, Himmelfarb J, Ikizler TA, Paganini EP, Mehta RL: Fluid accumulation, survival and recovery of kidney function in critically ill patients with acute kidney injury. Kidney Int 2009;76:422-427.

13 Fülöp T, Pathak MB, Schmidt DW, Lengvárszky Z, Juncos JP, Lebrun CJ, Brar H, Juncos LA: Volume-related weight gain and subsequent mortality in acute renal failure patients treated with continuous renal replacement therapy. ASAIO J 2010;56:333-337.

14 Boyd JH, Forbes J, Nakada TA, Walley KR, Russell JA: Fluid resuscitation in septic shock: a positive fluid balance and elevated central venous pressure are associated with increased mortality. Crit Care Med 2011;39:259-265.

15 Bagshaw SM, Brophy PD, Cruz D, Ronco C: Fluid balance as a biomarker: impact of fluid overload on outcome in critically ill patients with acute kidney injury. Crit Care 2008;12: 169.

16 Ronco C, Brendolan A, Bellomo R: Online monitoring in continuous renal replacement therapies. Kidney Int Suppl 1999;72:S8-S14.

17 Tonelli M, Astephen P, Andreou P, Beed S, Lundrigan $\mathrm{P}$, Jindal K: Blood volume monitoring in intermittent hemodialysis for acute renal failure. Kidney Int 2002;62:1075-1080. 
18 Du Cheyron D, Lucidarme O, Terzi N, Charbonneau P: Blood volume- and blood temperature-controlled hemodialysis in critically ill patients: a 6-month, case-matched, open-label study. Blood Purif 2010;29:245251.

19 Merouani A, Kechaou W, Litalien C, Ducruet $\mathrm{T}$, Jouvet P: Impact of blood volume monitoring on fluid removal during intermittent hemodialysis of critically ill children with acute kidney injury. Nephrol Dial Transplant 2011; 26:3315-3319.

20 Du Cheyron D, Terzi N, Seguin A, Valette X, Prevost F, Ramakers M, Daubin C, Charbonneau P, Parienti JJ: Use of online blood vol- ume and blood temperature monitoring during haemodialysis in critically ill patients with acute kidney injury: a single-centre randomized controlled trial. Nephrol Dial Transplant 2013;28:430-437.

21 Steuer RR, Bell DA, Barrett LL: Optical measurement of hematocrit and other biological constituents in renal therapy. Adv Ren Replace Ther 1999;6:217-224.

22 Yessayan L, Yee J, Frinak S, Szamosfalvi B: Online hemoglobin and oxygen saturation sensing during continuous renal replacement therapy with regional citrate anticoagulation. ASAIO J 2014, Epub ahead of print.
23 Kron S, Wenkel R, Leimbach T, Aign S, Kron J: Effects of sodium on measuring relative blood volume during hemodialysis differ by techniques. ASAIO J 2013;59:612616.

24 Santoro A, Mancini E, Paolini F, Zucchelli P: Blood volume monitoring and control. Nephrol Dial Transplant 1996;11(suppl 2): 42-47.

25 Iwaki $\mathrm{H}$, Okahisa T, Murata M, Miyamoto $\mathrm{H}$, Kuroda M, Ohnishi Y, Nishimura M, Akutagawa M, Kinouchi Y, Ito S: Influence of lipid emulsion for the hematocrit value measured with continuous hematocrit monitor. ASAIO J 2007;53:474-478. 